\title{
Aula em equipe como estratégia inovadora de ensino*
}

\section{Alberto Merchede}

Palavras-chave: dinâmicade grupo; método deensino; seminário; técnica deensino.
Versão adaptada. Publicado, na versão original, com o título "Aula em equipecomo técnica altemativadeinstrução centrada emgrupo", narevistaUniversa, v. 6, n. 2, p. 171-191, jun. 1998.

\section{Resumo}

Retoma uma técnica al ternativa de instrução centrada em grupo, trabal ho já publicado, aperfei çoando-o, revendo-o e ampliando-o, mediante introdução de modificações, fruto de aval iações real izadas no correr do tempo, desde a sua publicação na versão origi nal . A técnica é cal cada na experiência e corporificada num processo evolutivo de ajustes e correções. Inicia-se com a abordagem de al guns aspectos do semi nário, em que a técnica encontrou sua idéia germinal. Destacam-se críticas sobre a freqüente má utilização do seminário. A seguir, expõe-se a Técnica de Aula em Equipe, sua definição, objetivos e suas diferentes etapas deapl icação: planejamento, preparação, apresentações eaval iação. São tecidas considerações a respei to da utilização da técnica, tais como a reação dos al unos; al guns aspectos incorporados à técnica como forma de correção de problemas anteriores ou impropriedades detectadas na utilização do semi nário. Nas conclusões, apontam-se al guns resultados positivos do uso da técnica.

\section{Introdução}

A demanda cada vez maior de habilidades profissionais vol tadas para o desempenho e para a prática exigeque os conteúdos trabal hados na escola mantenham-se estreitamente vinculados com a real idadee experiência de vida dos alunos. A tentativa deoperacional ização do conhecimento teórico deve constituir-se, portanto, em preocupação constante, não só por parte dos promotores da educação, mas também, e principalmente, por partedo educando, em especial no caso da formação eaperfeiçoamento profissional.

A esse respeito, Demo (1992, p. 28), tratando sobre a formação de educadores, enumera como um dos "pontos cruciais" de uma proposta para colocar a educação como farol da tecnol ogia emodernidade, a seguinte observação: "a prática deve ser curricular desdeo primei ro semestre, como complemento necessário da teoria e viceversa, devendo ser devidamenteteorizada". Defato, quando o conhecimento teórico éal ienado da prática, corre o risco de tornar-se inócuo eineficaz, uma vez que compromete o atingimento dos objetivos da formação pretendida, representando, portanto, desperdício de esforços e de recursos.

A operacional ização aqui tratada deve considerar que, no papel do professor, está embutida a idéia de resposta aos desafios de uma sociedademoderna, industrializada, em quese val oriza mais o espírito crítico promotor de indagação do que a boa memória e a confiança cega na pal avra depositária da verdade (Cunha, 1992, p. 157). A exercitação do conhecimento teórico deve-seinserir num contexto que incl ua a capacidade de elaboração própria, construção criativa, "cultivando o ambiente moderno do 'aprender a aprender', para fugir do 'ensinar a copiar"' (Demo, 1992, p. 23). 
A prender não consiste em incorporar informações já construídas e, sim, em redescobri-las e reinventá-las pela própria atividade do sujeito (Castorina apud Davis, Espósito,1990, p. 73).

Essa concepção deveiniciar-se no planejamento do ensino, momento em que são estabel ecidos os objetivos, as estratégias, as técnicas de aval iação e os instrumentos a serem empregados. Lopes (2000, p. 45), em sua proposta de planejamento educacional participativo, afirma que, uma nova al ternativa para um planejamento de ensino gl obalizante, que supere sua dimensão técnica, seria a ação resultante de um processo integrador entre escola e contexto social, efetivada de forma crítica etransformadora.

E sob essa ótica, é sempreimportante refletir sobre como vivenciar no cotidiano da sal a de aula as técnicas pedagógicas de ensino, de avaliação, etc., que vão sendo incorporadas paulatinamente, no decorrer do aperfeiçoamento profissional , ao acervo teórico do conhecimento pessoal. E não é diferente com relação à técnica que se pretende aqui expor. Ela nasceu da tentativa de di recionar a conhecida técnica de seminário para uma proposta pedagógica própria, diferente, portanto, do que seconhece e do que se aplica com o nome de seminário.

Cal cada na experiência, a Técnica de Aula em Equipe - utilizada desde o início no ensino superior - decorre de um processo evolutivo de ajustes e acomodações. A cada oportunidade de aplicação da técnica, tem-se buscado, a partir da leitura, interpretação e discussão dos resultados, sempre com a partici pação dos alunos, corrigir, redirecionar ou modificar al gum aspecto que eventualmente possa ser melhorado, ou incorporar al go novo, contextual. Esses ajustes e correções permitiram contornar muitas dificuldades e problemas - adiante abordados - que podem ocorrer com a operacionalização do seminário, tais como: fragmentação do tema; superficial idade no tratamento do assunto; dificuldade em avaliar a partici pação dos integrantes; transferência dos encargos do professor para os alunos; falta de motivação, etc.

\section{Alguns aspectos do seminário}

Não existeumaforma padrão desemi nário, tampouco uniformi dade na sua concepção. Trata-sedeuma técnica queultimamente tem sido bastante utilizada em cursos degraduação, pós-graduação, encontros, congressos, etc. Compreende, de um modo geral, pesquisa, discussão e debate de um texto ou tema. Os autores o enfocam de diversas maneiras. Por exemplo, segundo Severino (1996, p. 63), o objetivo último do seminário élevar todos os participantes a uma re flexão aprofundada de determinado problema, a partir detextos eem equipe. Para Veiga (1996, p. 109), a maior contribuição do seminário talvez seja a de possibilitar que a prática repetitiva e acrítica dê lugar a uma prática pedagógicareflexiva ecrítica, deixando de lado o fazer pel o fazer ou o fazer fundamentado no modismo.

Pádua (1995, p. 140) aponta o debate como a parte mais importante do seminário, pois éo momento que leva à reflexão, à crítica, ao confronto de posições, que leva ao aprofundamento do conteúdo do texto e à aprendizagem; gera novas idéias, desperta curiosidades dos participantes a novos questionamentos sobreo assunto, etc.

O seminário dirige-se mais para a formação do que para a informação, pois visa capacitar o educando a estudar por si só, uma vez que dá ênfase ao uso dos instrumentos de trabal ho, à análise dos fatos, à refl exão sobre os problemas; ao pensamento original eà exposição dos trabal hos real izados com ordem, exatidão e honestidade (Nérici,1991, p. 287).

Em suma, al ém do aspecto cognitivo da produção do conhecimento, o semi nário permite ampliar a social ização; desenvolver a capacidade de investigação, a crítica ea autonomia eindependência intelectual; ea assumir responsabilidades em relação a si e aos outros.

Veiga (1996, p. 106) define seminário sob duas dimensões. A primeira, no sentido amplo: semi nário signi fica um congresso científico, cultural ou tecnológico, um grupo relativamente numeroso de pessoas (educadores, especial istas, etc.) com o propósito de estudar um tema ou questões de uma determinada área, sob a coordenação de uma comissão de educadores, especialistas ou autoridades no assunto. A segunda, no sentido restrito, onde seminário é 
visto como técnica deensino socializado: é o grupo de estudos em que se discute e se debate um ou mais temas apresentados por um ou vários al unos, sob a direção do professor responsável pela disciplina.

Para evitar mai ores del ongas na apresentação de diferentes definições de seminário, é interessante apontar o que de comum nelas se observa, queéa inclusão da pesquisa, discussão e debate. Outro aspecto também característico dessa técnica é a necessidade de participação de todos os integrantes. Para Pádua (1995, p. 137-139), o seminário visa "envolver todos os participantes". Esseenvol vimento diz respeito não só às discussões e debates sobre o tema, mas também à preparação de todos os participantes, por meio do estudo do assunto que vai ser debatido. Esteúltimo autor sugere, para um primeiro seminário, que "todos preparem o texto-roteiro, para se familiarizarem com a técnica". ${ }^{1}$

Rodrigues Júnior (1989, p. 1), recorrendo a Cirigliano e Villaverde e Hoover, aponta como traço comum entre eles o entendimento dequeno semi nário "não existem apresentadores nem ouvintes. Todos são participantes, ou seja, todos são apresentadores". E prossegue afirmando que o seminário é uma abordagem institucional "cujo motor é a própria classe e todos os alunos têm igual responsabilidade em contribuir e participar" (grifo nosso).

Entre as críticas a respeito do uso inadequado do seminário como técnica deensino, Balzan (apud Veiga, 1996, p. 107), afirmando que "seminário significa aula expositiva dada pelos alunos", aponta alguns equívocos no uso da técnica:

- tentativa mal fundamentada desubstituir o monól ogo do professor pel o monólogo do al uno;

- extrema divisão do trabalho, descontinuidade e fal ta de integração; e

- fica-seem generalidades, superficia lidades. O trabal ho conjunto de investigação passa a ser substituído por algo nãoproblematizante.

Uma outra crítica, queéformulada por Rodrigues Júnior (1989, p. 2), diz respeito à fal ta de preparo adequado tanto por parte do professor como dos alunos. Essa, aliás, é uma das causas do insucesso de al guns semi nários. Segundo o autor, "existe uma crença difundida nos meios universitários de queseminários são um recurso que professores usam para livrar-se da responsabilidade com a instrução, transferindo tal responsabilidade para os al unos".

Para prevenir contra o insucesso no uso do seminário, o autor do presente trabal ho sugere al gumas orientações, como por exemplo: real ização deensaio ou prévia do seminário (posto em prática por alguns professores); que o coordenador do seminário seja o professor; e outras. Nérici (1989, p. 252) enumera entreos componentes do semi nário a figura do diretor, "quase sempre um especialista em determi nada disci plina", que se propõea preparar cientificamenteum grupo de educandos e orientá-los até mesmo para a pesquisa original e avançada. Para Veiga (1996, p. 109), cabe ao professor aprofundar o assunto, 'tendo em vista o estudo anal ítico das idéias do autor, estabelecer relações, levantar hipóteses, provocar o al uno, encaminhar conclusões, enfim, conduzir o seminário". O seminário, portanto, constitui-se um processo dirigi do, cabendo ao seu orientador, diretor ou professor (qualquer que seja a denomi nação) um papel de suma importância, fazendo-o acontecer.

Quanto à avaliação, Pádua (1995, p. 143-144) propõequeseja real izada pel os três segmentos que partici pam da atividade: professor, grupo responsável e demais participantes. Devem ser avaliados, por exemplo, preparação, atingimento dos objetivos, participação, texto-rotei ro, real ização, etc. Veiga (1996, p. 112) também considera quea"apreciação final " sobre o trabal ho real izado seja feita tanto por parte dos responsáveis pelo seminário edemais partici pantes quanto por parte do professor. Para Antunes (1972, p. 179), seria importante efetuar uma "provinha objetiva" geral eaos pontos obtidos pelos grupos, o professor somaria outros, produto de suas observações sobre o trabal ho de cada um.

Muito embora na literatura apresentem-se os aspectos a serem aval iados e indiquem-se al gumas formas de avaliação, a tarefa avaliativa, no entanto, "é praticada em poucos seminários" (Rodrigues Júnior, 1989, p. 3).

\section{Aula em equipe}

\section{Definição}

A Técnica de Aula em Equipe, apesar de muitas vezes ser confundida, pela semeIhança, com a de semi nário, dela difere em muitos pontos. Trata-se de uma técnica de 
instrução também centrada em grupos eno al uno, na qual, entretanto, os al unos apresentam um tema, baseado em fontes bi bliográficas, em forma de aula expositiva.

Entendendo estratégia como os meios que o professor utiliza em sal a de aula para facilitar a aprendizagem dos alunos e que incluem normalmente o que se chama de metodol ogia de sala de aula, de técnica de ensino, de técnica pedagógi ca e de método didático (A breu, Masetto, 1990, p. 50-51) caracterizariaa Técnica de Aulas em Equipe como uma estratégia inovadora queseinsere no contexto de uma escolarização mais ampla, deumaaprendizagem global, quevisa não somentecontemplar aspectos cognitivos, mas também afetivos, psicomotores e motivacionais.

\section{Objetivos}

Os objetivos da escolarização, segundo Davis e Espósito (1990, p. 71), podem ser agl utinados em três grandes segmentos, quese referem a:

a) obtenção de informações sobre as conquistas de gerações precedentes (apropriação dos dados sobre a realidade);

b)construção de funções cognitivas (pensar e atuar crítico, autônomo e independente); e

c) el aboração de atitudes eval ores (escol ha lúcida, consciente e responsável de conduta pessoal esocial).

É dentro dessa ótica que, por meio da Técnica de Aula em Equipe, se pretende buscar o desenvol vimento das capacidades dos al unos, tais como a compreensão da lejtura; o pensamento crítico; a habilidadepara pesquisa; a construção propriamentedita do conhecimento (que é o ganho acadêmi co); as aptidões; as potencial idades, etc.

Os objetivos específicos podem ser desdobrados em:

- pesquisar, ensinar a pesquisar e estimular o hábito da leitura;

- desenvolver a capacidade de pesquisa, organização e análise sistemática dos fatos;

- despertar o hábito da reflexão, possibilitando a apresentação, organizada de forma própria, com coerência e consistência, detemas;
- participar do trabal ho cooperativo, integrando-se nas diversas fases do seu desenvolvimento econtribuindo paraos resultados;

- despertar a capacidadedeexpressar-se com desembaraço perantegrupo depessoas;

- atingir os objetivos planejados para o tópico ou tema objeto da Aula em Equipe.

\section{Planejamento}

O planejamento do Ciclo de Aulas em Equipe, a cargo quase que exclusivamente do professor, tem como referencial o conteúdo programático da disci plina objeto de aplicação da técnica e os objetivos a serem al cançados. O planejamento basicamente compreende:

a) elaboração eapresentação à turma do cronograma detodas as atividades tais como: preparação, apresentação, testes, discussão eaval iação;

b) definição da bibliografia mínima a ser indicada (a ampliação da bi bl iografia ficará a cargo das equipes);

c) constituição dos grupos (em geral aproveitam-se os grupos já constituídos) e escol ha de um coordenador, que pode ser aclamado, e de seu substituto;

d) elaboração do guia de estudos, a ser apresentado e entregue à turma com antecedência necessária para que todos os participantes possam tomar conhecimento das "regras" do jogo (Anexo 1); e

e)fixação antecipada (no guia de estudos), do tempo a ser destinado às apresentações. A ampliação ou redução desse tempo é negociada em oportunidade posterior, durante o desenvolvimento dos trabal hos, quando a turma está mais consciente do grau de dificuldade e da necessidade de tempo para as apresentações. Essa negociação geralmente ocorre juntamente com a avaliação do planejamento do curso e conseqüente revisão do Plano de Ensino.

\section{Preparação}

O processo inicia-selogo nas primeiras aulas do semestre, com vistas a propiciar mai or prazo para pesquisas e estudos. Durante o período preparatório, é reservado, em cada aula, espaço destinado exclusivamente à preparação do trabalho, sob orientação do professor. Além disso, também é 
reservada uma sessão integral (mais ou menos 80 minutos) especial mente para desenvolvimento dos trabal hos, incluindo ensaio, de modo a preparar e desinibir os futuros apresentadores de temas. As tarefas compreendem leitura eexplicação de pequenos textos indicados pel o professor; recitação de poemas; apresentação decasos de experiências pessoais; dramatizações e outras. Esse acompanhamento emonitoramento, por partedo professor, possi bilita-lhetomar conhecimento do grau de desenvol vimento do aluno eseu nível de participação.

Nessa fase também são discutidos: a forma deapresentação dos tópicos; os princi pais itens em que cada tópico será subdividido; a fixação do tempo de apresentação de cada item; a escolha dos recursos de apoio a serem utilizados (quadros, painéis, transparências, slides, etc.). O tema decada equipeédividido em tantas partes (ou itens) quantos forem os componentes dos grupos. O dimensi onamento dessas partes leva em conta a necessidade de distribuição eqüitativa do tempo de apresentação ea magnitude do conteúdo.

No entanto essas partes não são distribuídas previamente. Ao contrário, os alunos são orientados no sentido de que cada elemento da equi pe deve estar preparado; conhecer o tema e dominar o assunto com suficiente profundidade para apresentá-lo sozinho. Essa orientação, além de constar do guia de estudos, é enunciada repetidas vezes durante a fase preparatória.

Ainda nessa faseé material izado o tra balho escrito - indicando as fontes bi bliográficas pesquisadas - a ser distribuído com antecedência mínima, de modo a permitir que os demais integrantes da turma preparem-se, com antecedência, para participar da aula.

\section{Apresentações}

As apresentações iniciam-se com o sorteio, para efei to de distribuição, entre os componentes da equipe, das partes a serem expostas. No caso de ausência de al gum componente, o item remanescente será sorteado entre os presentes. A seguir, o professor introduz o assunto e entrega a condução dos trabal hos à equi pe apresentadora. Os demais al unos que assistem à apresentação, acompanham-na apoiados no material previamentedistribuído ou diretamente nas fontes bibliográficas indicadas. As exposições são acompanhadas pelo professor que, nas ocasiões oportunas (durante ou após a apresentação), aborda aspectos ou pontos não incluídos ou insuficientemente aprofundados, de modo que, suprida a fal ha ou insuficiência, o assunto torne-se passível de ser considerado como matéria ministrada, para efeito de avaliação individual. Trata-se, portanto, de uma aula expositiva, onde os al unos que a el a assistem podem abordar outros aspectos, levantar debates, solicitar esclarecimentos, etc. A divulgação prévia dessas condições desperta interesse dos al unos em dispensar mai or atenção e participação na apresentação, mesmo porque, logo após a apresentação do tema, a turma será submeti da a teste sobre o assunto, conforme adiante explicado.

\section{Avaliação}

Os resul tados são aval iados não só de forma estática, instantânea, fotográfica, mas como na cinematografia, por meio decenas sucessivas, ao longo do processo ensinoaprendizagem. Trata-se da avaliação formativa, queé aquela feita duranteo decorrer da aprendizagem, quando ainda se podem corrigir as fal has, tanto do professor como do al uno, ou até mesmo do método ou do planejamento. Dentro desse entendimento, é sempre concedida uma segunda oportunidade, após revisão do assunto, a al uno cujo desempenho se mostre insatisfatório.

A sistemática de aval iação aqui utilizada foi concebida de modo a fugir da indesejável linearidade, ou seja, no estabel ecimento do mesmo diagnóstico parasintomas diferentes. A parti cularização de cada aspecto a ser avaliado, conforme adiante descrito, busca evitar, entre outras coisas, que a timidez ou dificuldade demanifestação venha a inibir eprejudicar a aval iação deoutros aspectos.

No decorrer do processo avaliativo, a pontuação atribuída nas di ferentes etapas ou episódios, em val ores proporcionais ao seu grau de significado no contexto da aprendizagem, i rá compor a média final.

A avaliação do Ciclo de Aulas em Equipe compreende três componentes. Os dois primeiros são chamados deatuação docente, que é a atuação dos grupos apresentadores (avaliada, respectivamente, pelo professor e 
pelos próprios alunos) e a outra, aproveitamento discente, é feita por meio de teste escrito. A nota final do ciclo éa média ponderada desses três componentes, cujos pesos são os seguintes:

a) a atuação docente avaliada pelo professor, tem peso 6. Nesta aval iação, a nota de cada al uno é composta por duas parcel as: a nota do grupo (máximo de 3 pontos) e a do aluno (máximo 7 pontos), em quesão avaliados os aspectos adiante descritos;

b)a atuação docente avaliada pelo próprio grupo apresentador, tem peso 2 e as notas são individuais; e

c) o aproveitamento discente érepresentado pela média aritmética dos testes individuais, aplicados no final de cada apresentação, em sal a de aula, ${ }^{2}$ etem peso 2.

Atuação docente avaliada pelo professor, conforme explicado, consiste numa aval iação mista, enfocando tanto o grupo como individual mente cada expositor. Inclui os itens seguintes e as respectivas pontuações:

a) Avaliação da equipe (pontuação máxima: 3 pontos):

a.1) Organização da apresentação (1 ponto) - Compreende a preparação dos trabal hos ea montagem não só da apresentação, mas também detodo o material deapoio edo resumo a ser distribuído previamente à turma. Inclui os ensai os e a organização das partes do tema a serem sorteadas entre os apresentadores. Deve ser considerada a criatividade do grupo quanto à forma de apresentação do trabal ho.

a.2) Nível de aprofundamento (1 ponto) - Refere-se ao nível de abrangência e diversificação do conteúdo tratado, bem como da abordagem dispensada ao tema, como resultado da denotada plural idade das fontes de consulta. Aqui está incluído o domínio coletivo (por parte do grupo) do assunto, o que contempla eventual necessidade de escl arecimentos de dúvi das, quando o apresentador não o fizer. A falta de esclarecimento será ponderada negativamente para o apresentador, no item "Domínio do assunto".

a.3) Aproveitamento discente (1 ponto) - Representa o reflexo do aproveitamento da turma na pontuação da equi pe expositora. Essa pontuação éfixada deacordo com a média da nota do teste de aproveitamento discentequeéaplicado à turma após a apresentação. Conforme mostra o esquema de pontuação constante do Anexo 1, sea média das notas do teste deaproveitamento discente situar-seentre 8 e 10, a equipe expositora obterá 100\% da pontuação do item (queéde 1 ponto). Essa pontuação vai caindo, à medida que cai o aproveitamento discente.

b) Avaliação do aluno (pontuação máxima: 7 pontos):

b.1) Domínio do assunto (2,5 pontos) O domínio do assunto deveser demonstrado por meio da coerência da argumentação, consistência esegurança no desenvol vimento da abordagem do tema, o queincl ui o esclarecimento satisfatório das dúvidas suscitadas. Caso o apresentador não esclareça as dívidas, a tarefa caberá ao restante da equipe. A de monstração do domínio individual do assunto deve iniciar-se já na fase preparatória. Os al unos são convidados, al eatoriamente, a pronunciarem-senessafase dos trabal hos.

b.2) Capacidade de expressão (1 ponto) - Compreende a capacidade de comunicação, não só quanto à fluência ecorreta utilização da linguagem, mas também quanto ao encadeamento coerente do assunto, com cla reza e objetividade das idéias.

b.3) Participação (1,5 ponto) - É o envolvimento do indi víduo na organização eno desenvol vimento dos trabal hos, inclusive quanto ao comparecimento às seções de preparação em sala de aula. Esta avaliação inicia-se também na fase preparatória.

b.4) Disciplinamento do tempo (0,5 ponto) - Disciplinamento do uso do tempo cujos limites, inclusive tolerância, são fixados previamente, por ocasião do planejamento do Ciclo de Aulas em Equipe.

b.5) Motivação da turma (1,5 ponto) Compreende a capacidade de motivar o envolvimento da turma, seja suscitando diálogo interativo e argüições, seja problematizando situações, de modo a provocar a participação e o debate. É uma oportunidade de exercitar a capacidade criativa do expositor.

As notas são atribuídas particularizadamente para cada um dos aspectos sob avaliação, de modo que a soma das notas máximas seja igual a 10, conformemostra o modelo constante do Anexo 2, queéo Apanhado das Notas das A presentações. A magnitude da pontuação depende da importância do aspecto que está sendo avaliado. O

\footnotetext{
O Anexo 3 contém modelo de testedeaproveitamentodiscente
} 
model o éutilizado duranteas apresentações, para atri buição das notas aos grupos expositores. Os dados nel e contidos são utilizados para preenchimento do mapa final denotas, denominado Mapa de A puração das Notas do Ciclo de Aulas em Equipe (Anexo 3).

A aval iação começa desdeos trabal hos preparatórios de "montagem" do semi nário, que, sob a orientação do professor, deverão ocorrer, como foi mencionado, em sala de aula.

Com rel ação à aval iação do aprovei tamento discente, procede-se da seguinte maneira. São constituídas, de um modo geral, seis ou sete equipes compostas por cinco ou seis el ementos cada uma. O número de temas, conforme foi mencionado, correspondeà quantidade de equipes. Por isso, seforem apresentados, por exemplo, cinco temas, cada equipe deverá ser submetida a quatro testes de aproveitamento discente, que correspondem à parti ci pação da equipe na apresentação das outras quatro.

\section{Considerações sobre a aplicação da técníca}

Conformefoi exposto ao longo destetrabalho, a técnica apresentada foi-se corporificando no decorrer de um processo evolutivo de aperfeiçoamento do uso do seminário, nas sucessivas buscas de correções de problemas eimpropriedades detectadas.

A identificação de aspectos passíveis de correções ou ajustes ocorre quase semprea partir do resul tado das aval iações, do acompanhamento da efetiva operacional ização da técnica e conseqüente confronto dos resultados com os propósitos inicial menteidealizados e planejados. Esses resultados, que abrangem normal mente todas as etapas do ciclo de aula em equipe - desde a preparação até a aval iação - são discutidos com os participantes, cujas contribuições passam a ser objeto de refl exão e posteriormente podem integrar modificações eajustes que vão sendo incorporados em ciclo subseqüente de uso da técnica.

A esse respeito é oportuno destacar as principais inovações incorporadas à técnica, concebi das como solução ou correção de problemas, impropriedades ou críticas feitas ao seminário, abordadas no início deste trabalho.
A primei ra delas consistena real ização do sorteio, somente no momento da apre sentação, para distribui ção da parte do tema que caberá a cada expositor. Essa medida objetiva evitar que a repartição antecipada do tema enseje tratamento fragmentado do assunto, bem como o estudo ea preparação desintegrada das partes. Com isso, pretende-se preservar a integridade da compreensão e do tratamento do assunto. Sobre essa preocupação, o guia de estudos contém orientações bem objetivas.

Verificou-se que uma das primeiras re ações que ocorrem quando da apresentação das orientações sobre a técnica, foi exatamentequanto à não-distribuição antecipada das partes do tema. Os al unos reclamam por terem que estudar o tema como um todo; prefeririam especializarem-se cada qual na sua parte, como estão acostumados a fazer.

Uma outra inovação consiste na aplicação do teste de aproveitamento aos participantes discentes. A inovação foi concebida como solução para evitar o monól ogo e tratamento superficial e nãoproblematizante do assunto. Busca-se, com isso, despertar o interesse de todos a se envolverem com o tema, estabel ecendo diál ogo com os expositores, para esclarecimento de dúvidas ou debates sobreal guns aspectos a serem clarificados. Sabendo antecipadamente que o assunto será objeto de verificação de aprendizagem, o interesse pela compreensão, aprofundamento, entendimento e busca de esclarecimentos passa a ser mai or, conforme foi mencionado, evitando a postura de meros "ouvintes".

Os ensai os têm sido um recurso muito útil, uma vez que possibilitam maior interação da turma e despertam a capacidadedecomunicação. Inicial mente, ocorreum encontro ( \pm 30 minutos) de descontração. Os al unos lêem textos escol hidos na ocasião, recitam poemas, etc. Todos são convidados a partici par. O al uno deve, por exemplo, explicar o queentendeu da leiturafeita pel o col ega. Caso não o consiga, fará ele a leitura no ritmo, entonação eforma com que gostaria de ter ouvido. Dessa manei ra vãoserevezando, atéquetodos tenham participado. Em sessão posterior, quando já se dispõe de algum material pronto sobre os trabal hos, si mulam-securtas apresentações, mesmo queainda parciais. Nessas prévias, já vão sendo corrigidos alguns eventuais erros.

Essa providência, bem como o acompanhamento emonitoramento, por partedo 
professor durantetodo o desenvol vimento dos trabal hos, passa ao largo da crença, inicialmente citada, sobre o uso do semi nário como recurso empregado pelo professor, para livrar-se da responsabilidade com a instrução, transferindo-a para os al unos.

Um outro aspecto introduzido diz respeito ao esquema de pontuação, concebido de maneira a desencorajar o al uno a desobrigar-se de sua partici pação e apoiar-seno grupo. Essa é outra crítica quanto ao emprego do seminário. O participantequeassim agir estará sujeito a garantir, no máximo, apenas 30\% da pontuação gl obal, pois os restantes $70 \%$ são direcionados para o desempenho individual, conformecritério de pontuação já exposto.

A mais recente inovação introduzida diz respeito à reformul ação dos aspectos da atuação docente avaliados pelo professor, tanto rel ativamenteao desempenho do grupo como do aluno. A principal alteração consistiu na introdução de item que estimule a pesquisa e o aprofundamento no estudo e tratamento do tema (item "Nível de aprofundamento"). Foi também incluído item específico para aval iar a participação eenvolvimento do al uno nos trabal hos (item "Participação").

\section{Conclusões}

A técnica ora exposta obviamente não representa al go novo, mastão-somenteuma inovação, sobretudo quanto ao processo aval iativo, no emprego da técnica do seminário. Por outro lado, embora tenha introduzido uma inovação quanto à particularização dos aspectos avaliados, de modo a fugir da linearidade da aval iação, não se pretendeu, também, preencher alacuna de métodos verdadeiramenteindividual izados, como defendido, por exemplo, por Coll, quando, ressal tando que a amplitudee variedade das diferenças individuais e sua repercussão sobre a aprendizagem escolar são fatos reconhecidos e aceitos desde a antigüidade, recomenda quesedeverenunciar a prescrever um método de ensino único e aplicável a todos os alunos (Coll, 1996, p. 133).

A Aula em Equipe, como foi dito no início, por assemel har-se com o semi nário, émuitas vezes com el econfundida, recebendo seu rótulo, mas dele diverge em muitos pontos. Diferentemente do que se afirma quanto a professores utilizarem-se do seminário para transferir suas responsabilidades coma instrução aos al unos, no caso da técnica ora apresentada, o professor desempenha um papel mais ativo, com laboriosos encargos, que lhe exigem completo e permanente envol vimento, compreendendo, por exemplo: planejamento; preparação; coordenação das atividades desenvol vidas em todas as etapas; treinamento (inclusiveensaios); acompanhamento; correção de rumos, quando necessário; avaliação eoutras.

Além dos resultados relativos aos desempenhosmensuráveisequantificáveis por meio dasistemática aval iativa descrita, outros efeitos colaterais têm sido freqüentementeevidenciados no comportamento dos al unos. I dentificam-semodificações comportamentais que quasesempresuperam o campo estritamente cognitivo e vão al cançar o desenvolvimento deoutras potencial idades, como a habilidade deexpressão e manifestação espontânea; capacidadedepesquisar, estruturar, organizar e expor os assuntos, etc.

Há casos em quea capacidade demonstrada demotivar, decriar, deexpor, deorganizar edese expressar são surpreendentes, ultrapassando as expectativas não só quanto à abrangência do assunto, mas também com rel ação à profundi dade do tratamento. Vale a pena mencionar alguns casos. Uma das equipes, por exemplo, para motivar a turma, utilizou, ao final da apresentação uma espécie de joguinho, por meio de questionário resumindo a matéria exposta e oferecendo premiação (bombons) aos sorteados que respondessem satisfatoriamenteàs questões formuladas. Uma outra equipe valeuse da dramatização, envolvendo toda a turma e dela selecionando, por meio de teste curto, os participantes de um dos grupos como pseudocandidatos a um emprego. $\mathrm{O}$ treinamento dispensado a esses candidatos foi a apresentação do tema objeto da aula. O nível de preparo do grupo e a organi zação e profundidade no tratamento do tema despertaram interesse em que o assunto fosse apresentado (e o foi) pela mesma equipe em outro curso, numa disciplina equival ente.

Além da descoberta de capacidades de liderança, monitoramento, sintetização e organização dos assuntos, também são despertadas habilidadeartística de el aboração de painéis, de diagramação e formatação de transparências, edição de slides e outras vocações. Um aspecto gratificante quevale a pena também destacar diz respeito à mudança de comportamento daquel es alunos no início identificados como tímidos e retraídos, e que durante o desenvolvimento dos trabal ho vão-se descontraindo de tal 
modo que, ao final do curso, estão completamente integrados ao restante da turma, participando espontânea e ativamente das aulas dos outros grupos, inclusive.

\section{Referências bibliográficas}

ABREU, Maria Célia de; MASETTO, Marcos T. O professor universitário em aula: prática e princípios teóricos. 8. ed. São Paulo: MG Ed., 1990.

ANTUNES, Celso. Técnicas pedagógicas de dinâmica de grupo. Rio de Janeiro: Ed. do Brasil, 1972.

BALZAN, Newton César. Sete asserções inaceitáveis sobre a inovação educacional. Educação e Sociedade, São Paulo, n. 6, p. 19-30, jun. 1980, apud VEIGA, IIma Passos Alencastro. O semi nário como técnica deensino social izado. In: VEI GA, II ma Passos Alencastro (Org.). Técnicas de ensino: por que não? 4. ed. Campinas: Papirus, 1996. cap. 6, p. 103-113.

CASTORINA, J. A. et al. Psi col ogi a genética: aspectos metodológicos eimplicações pedagógicas. Porto Alegre: Artes Médicas, 1988, apud DAVIS, Cláudia; ESPÓSITO, Yara Lúcia. Papel efunção do erro na aval iação escolar. Cadernos de Pesquisa, São Paulo, n. 74, p. 71-75, ago. 1990.

COLL, César. Psicologia e currículo. São Paulo: Ática, 1996.

CUNHA, Maria Isabel da. O bom professor e sua prática. 2. ed. Campinas: Papirus, 1992.

DAVIS, Cláudia; ESPÓSITO, Yara Lúcia. Papel e função do erro na avaliação escolar. Cadernos de Pesquisa, São Paulo, n. 74, p. 71-75, ago. 1990.

DEMO, Pedro. Formação de educadores: inquirindo alternativas. In: GOMES, Cândido Alberto; AMARAL SOBRINHO, José(Org.). Qualidade, eficiência e eqüidade no ensino básico. Brasília: Ipea, 1992.

GODOY, Arilda Schmidt. Avaliação da aprendizagem no ensino superior: estado da arte. Didática, São Paulo, n. 30, p. 9-25, 1995.

LOPES, Antonia Osmina, Planejamento do ensi no numa perspectiva crítica deeducação. In: VEIGA, IIma Passos Alencastro (Coord.). Repensando a didática. 5. ed. Campinas: Papirus, 2000. p. 41-52.

NÉRICl, Imídeo G. M etodologia do ensino: uma introdução. 3. ed. São Paulo: Atlas, 1989. . Introdução à Didática Geral. 16. ed. São Paulo: Atlas, 1991.

PÁDUA, Elisabeth Matallo Marchesini de. Seminário. In: CARVALHO, Maria Cecília M. deConstruindo o saber: metodologia científica: fundamentos etécnicas. 5. ed. Campinas: Papirus, 1995. cap. 5, p. 137-146.

RODRIGUES JÚNIOR, José Florêncio. Notas sobre o seminário na prática acadêmica. Brasília: Universidade de Brasília, Núcleo de Desenvolvimento do Docente, 1989. Mimeografado.

SEVERINO, Antonio Joaquim. Metodologia do Trabalho Científico. 20. ed. rev. ampl. São Paulo: Cortez, 1996.

VEIGA, Ilma Passos Alencastro. O seminário como técnica deensino social izado. In: VEIGA, Ilma Passos Alencastro (Org.). Técnicas de ensino: por que não? 4. ed. Campinas: Papirus, 1996. cap. 6, p. 103-113. 
Alberto Merchede, mestreem Educação pela Universi dadeCatólica deBrasília(UCB), é professor dessa Universidade e coordenador de curso de Marketing e professor na Faculdade Euro-Americana.

merchede@euroamericana.com.br

\section{Abstract}

The problem of "cheating on tests" is not only a polemic one, but is al so full of controversy. This is so, when the subject is viewed both from a didactics and pupil evaluation perspective and from a human values perspective. Hence, "cheating on tests" constitutes a significant and challenging research theme. Thus, turning "cheating on tests" into a problem is to rethink it on a critical and strongly based way, which enables the perception and analysis of the several sides of its origin and circumstances. Bearing that on mind, that survey bases itself on the Social Representation Theory to discuss images, concepts, practices and tools as well as to study alternatives of that "problem", giving special attention to the interrelation between school and psychosocial reasons.

Keywords: social representation; "cheating on tests"; teaching; research.

Recebido em 5 de fevereiro de 2002.

A provado em 24 de junho de 2003. 


\section{Anexo 1}

\section{Exemplo do guia de estudos}

\author{
UNIVERSIDADE \\ Curso: \\ Disciplina: \\ Prof.:
}

TURMA:

ÉPOCA:

\section{CICLO DE AULAS EM EQUIPE}

\section{Guia de Estudos}

\section{Definições}

A presentetécnica consiste em que as equipes já constituídas na turma apresentem, em forma de aula expositiva, temas que lhes serão distribuídos. Os temas, a serem apresentados de acordo com a ordem estabel eci da no item 4 adiante, serão sorteados entre as equipes, às quais caberá a escol ha dos recursos a serem utilizados na exposição (quadros, transparências, painéis, slides, etc.). No entanto, a apresentação do trabal ho deverá ser real izada por todos os componentes de cada equipe. Os temas serão divididos em tantas partes quantos forem os integrantes das equipes, mas só serão distribuídos, mediante sorteio, por ocasião da apresentação.

Deve-se ter sempre em mente que a fil osofia básica desse tipo de técnica pressupõe quecada elemento da equi pe deve estar preparado; conhecer o tema e dominar o assunto com suficiente profundidade para apresentá-lo sozinho.

O tempo de apresentação (mínimo de 30 e máximo de 40 minutos) será dividido eqüitativamente entre os integrantes da equipe. A ampliação ou redução desse tempo pode ser negociada em oportunidade posterior, após a turma já estar desenvolvendo os trabal hos e, portanto, mais consciente do grau de dificul dadee da necessidade de tempo para as apresentações.

O trabal ho deverá ser desenvol vido dentro efora da sal a de aula, mediante acompanhamento e orientação por parte do professor. Serão reservados al guns horários de aula especificamente para esse fim, inclusive para escol ha dos recursos de apoio a serem empregados, divisão do tema, real ização de ensai os envolvendo todos os partici pantes, etc.

As exposições serão precedidas de:

a) distribuição do trabal ho escrito sobre o tema, com antecedência mínima de uma semana, para que o professor ea turma possam acompanhar;

b) discriminação do tempo e do conteúdo decada uma das partes a serem apresentadas;

c) sorteio, entre os partici pantes, da parte que caberá a cada um;

d) outros esclarecimentos eventual mentenecessários.

As apresentações serão acompanhadas pel o professor que, em ocasi ões oportunas (durante ou após a apresentação), abordará aspectos ou pontos não incluídos ou insuficientemente aprofundados, de modo que, suprida a fal ha ou insuficiência, o assunto torne-se passível de ser considerado como matéria mi nistrada, para efeito de aval iação individual . Também, os al unos queestiverem assistindo à apresentação podem abordar outros aspectos relevantes para melhor entendimento do tema; levantar, se for o caso, debates; solicitar esclarecimentos, enfim, participar efetivamente do desenvolvimento do assunto.

\section{Objetivos}

Ao final do Ciclo de Aulas em Equipe, os al unos estarão aptos a: 
- desenvolver pesquisas bi bliográficas de assuntos de seu interesse;

- organizar eanal isar as informações obtidas a partir da pesquisa;

- organizar eapresentar temas quel hesejam confiados;

- atingir os objetivos planejados para o tópico ou tema objeto decada Aula em Equipe.

\section{Avaliação}

A avaliação do Ciclo de Aulas em Equipe compreende três componentes e começa desde os trabal hos preparatórios de montagem do cicl o sob a orientação do professor. Os dois primei ros componentes são chamados de atuação docente, queéa atuação dos grupos apresentadores (aval iada, respectivamente, pelo professor e pel os próprios al unos) e a outra, aproveitamento discente, éfeita por meio de teste escrito. Estes três componentes têm os seguintes pesos:

a) A atuação docente avaliada pelo professor tem peso 6 . Nessa avaliação, a nota de cada al uno é composta por duas parcelas: a nota do grupo (máximo de 3 pontos) e a do al uno (máximo 7 pontos), em que são aval iados os aspectos adiante descritos;

b) A atuação docente avaliada pelo próprio grupo apresentador tem peso 2, e as notas são individuais.

c) O aproveitamento discente érepresentado pela média aritmética dos testes individuais, aplicados no final de cada apresentação, em sala de aula, ${ }^{1}$ e tem peso 2.

Atuação docenteaval iada pel o professor, conforme explicado, consistenuma aval iação mista, enfocando tanto o grupo como individual mente cada expositor, deacordo com esquema de pontuação a seguir apresentado. Inclui os seguintes itens:

a) Avaliação da equipe (pontuação máxima: 3 pontos):

a.1) Organização da apresentação (1 ponto) - Compreende a preparação dos trabaIhos ea montagem não só da apresentação, mas também de todo o material de apoio e do resumo a ser distribuído previamenteà turma. Inclui os ensaios e a organização das partes do tema a serem sorteadas entre os apresentadores. Será considerada a criatividade do grupo quanto à forma de apresentação do trabal ho.

a.2) Nível de aprofundamento (1 ponto) - Refere-seao nível deabrangência ediversificação do conteúdo tratado, bem como da abordagem dispensada ao tema, como resul tado da denotada plural idade das fontes de consulta. Aqui está incluído o domínio coletivo (por parte do grupo) do assunto, o que contempla eventual necessi dade de esclarecimentos de dúvidas, quando o apresentador não o fizer. Neste caso, a fal ta de esclarecimento será ponderada negati vamente, para o apresentador, no item Domíni o do assunto.

a.3) Aproveitamento discente (1 ponto) - Representa o reflexo do aproveitamento da turma na pontuação da equi pe expositora. Essa pontuação éfixada deacordo com a média da nota do teste de aproveitamento discente que éaplicado à turma após a apresentação, conforme mostra o esquema de pontuação apresentado ao final deste guia de estudos.

b) Avaliação do aluno (pontuação máxima: 7 pontos):

b.1) Domínio do assunto (2,5 pontos) - O domínio do assunto deve ser demonstrado por meio da coerência da argumentação, consistência e segurança no desenvolvimento da abordagem do tema, o queinclui o esclarecimento satisfatório das dúvidas suscitadas. Caso o apresentador não esclareça as dúvidas, a tarefa caberá ao restante da equipe. A demonstração do domínio individual do assunto deveini ciar-sejá na fase preparatória. Os al unos são al eatoriamente convidados a pronunciarem-senessa fase dos trabal hos.

b.2) Capacidade de Expressão (1 ponto) - Compreendea capacidadedeexpressar-se, não só quanto àfluênciae correta utilização dalinguagem, mas também quanto ao encadeamento coerente do assunto, com clareza eobjetividadedas idéias.

b.3) Participação (1,5 ponto) - Refere-se ao envol vimento do indivíduo na organização e desenvol vimento dos trabal hos, inclusive quanto ao comparecimento às seções de preparação em sal a de aula. A avaliação inicia-se também na fase preparatória.

\footnotetext{
1 O Anexo 4 contém modelo de testedeparticipação indireta.
} 
b.4) Disciplinamento do Tempo (0,5 ponto) - Disciplinamento do uso do tempo cujos limites, inclusive detolerância, são fixados previamente.

b.5) Motivação da turma (1,5 ponto) - Compreende a capacidade de motivar o envolvimento daturma, sejasuscitando diál ogo interativo eargüi ções, seja problematizando situações, demodo a provocar a partici pação eo debate. É uma oportuni dade de exercitar a capaci dade criativa do expositor.

As notas são atri buídas particularizadamente para cada um dos aspectos sob aval iação, de modo que a soma das notas máximas seja igual a 10, conforme consta do item 6 Esquema de pontuação. A avaliação começa desde os trabal hos preparatórios de montagem do semi nário, que, sob a orientação do professor, deverão ocorrer também em sal a de aula.

Ao final de cada apresentação, conformemencionado no item a.3 - Aproveitamento docente, será aplicado à turma um teste (exceto, evidentemente, aos apresentadores). A média desses testes équeirá constituir o aproveitamento discente (com peso 2).

\section{Temas e datas das apresentações}

A seguir estão relacionados os temas a serem sorteados, na ordem em que deverão ser apresentados. Convém consi derar que a estruturação da abordagem (itens, subdivisões, tópicos, forma, profundidade, etc.) será organizada e sugerida ao professor pel os componentes de cada equi pe, após seus membros terem al cançado visão gl obal da abrangência do tema, como resul tado das pesqui sas bi bl iográficas prel imi nares real izadas.

a) Tema no 1:

b) Tema no 2:

c) Tema no 3:

\section{Referências bibliográficas}

As seguintes referências bi bliográficas contêm material pertinenteaos temas indicados. Cada uma aborda assuntos de um ou mais temas. Trata-se apenas de sugestão mínima à qual não se develimitar o trabal ho. As equipes deverão enriquecer a pesquisa buscando outras fontes. O resultado dessa diversificação estará sendo avaliado, conforme consta do item a.2 - Nível de aproveitamento. As fontes indicadas são, portanto:
a) Obra $\mathrm{n}$ - 1
b) Obra no 2
c) Obra oㅡ 3

\section{Esquema de pontuação}

\begin{tabular}{|c|c|}
\hline \multicolumn{2}{|c|}{ PONTUAÇÃO (Máxima) } \\
\hline $\begin{array}{l}\text { 1. Do grupo: } \\
\text { Organização da apresentação ............. 1,0 } \\
\text { Nível de aprofundamento .................. 1,0 } \\
\text { Aproveitamento discente .................. } 1,0\left(^{*}\right) \\
\text { Total }\end{array}$ & 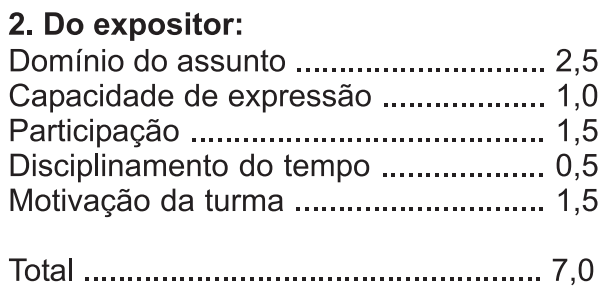 \\
\hline
\end{tabular}

\begin{tabular}{|c|c|}
\hline (*) Média da turma no teste & $\begin{array}{c}\text { Pontuação correspondente } \\
\text { (do grupo expositor) }\end{array}$ \\
\hline Acima de 8 até 10 & 1,0 \\
Acima de 6 até 8 & 0,8 \\
Acima de 4 até 6 & 0,5 \\
De 4 abaixo & zero \\
\hline
\end{tabular}




\section{Anexo 2}

\section{Exemplo do apanhado das notas das apresentações}

UNIVERSIDADE.

Curso:

Disciplina:

Prof.:
TURMA:

ÉPOCA :

\section{CICLO DE AULAS EM EQUIPE}

\section{Apanhado das Notas das Apresentações}

\begin{tabular}{|c|c|c|c|c|c|c|c|c|c|c|c|}
\hline \multicolumn{12}{|c|}{ Equipe $n^{0}$ 1: Data da apresentação: Tema: Principais funções administrativas } \\
\hline \multirow{2}{*}{ 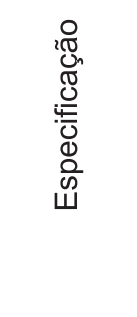 } & \multicolumn{4}{|c|}{ Pontuação do grupo } & \multicolumn{6}{|c|}{ Pontuação individual } & \multirow[b]{2}{*}{ 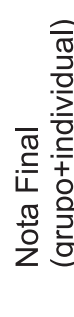 } \\
\hline & 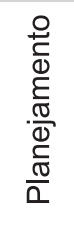 & 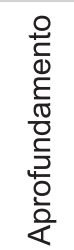 & 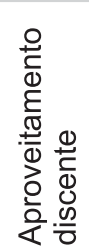 & 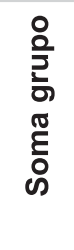 & 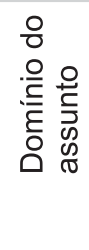 & 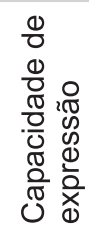 & 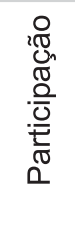 & 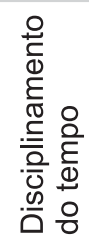 & 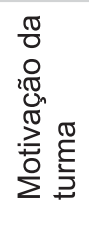 & 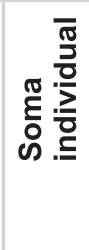 & \\
\hline Aluno 5 & 1,0 & 0,5 & 0,5 & 2,0 & 2,0 & 1,0 & 0,5 & 0,5 & 0,6 & 4,6 & 6,6 \\
\hline Aluno 11 & 1,0 & 0,5 & 0,5 & 2,0 & 2,0 & 0,5 & 1,5 & 0,5 & 1,5 & 6,0 & 8,0 \\
\hline Aluno 12 & 1,0 & 0,5 & 0,5 & 2,0 & 1,0 & 0,5 & 1,0 & 0,5 & 1,0 & 4,0 & 6,0 \\
\hline Aluno 21 & 1,0 & 0,5 & 0,5 & 2,0 & 2,5 & 1,0 & 1,5 & 0,5 & 1,5 & 7,0 & 9,0 \\
\hline
\end{tabular}

\begin{tabular}{|c|c|c|c|c|c|c|c|c|c|c|c|}
\hline \multicolumn{12}{|c|}{ Equipe $n^{\circ} 2$ : Data da apresentação: Tema: Funções empresariais } \\
\hline \multirow{2}{*}{ 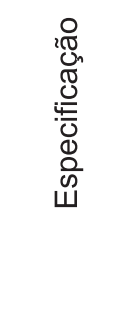 } & \multicolumn{4}{|c|}{ Pontuação do grupo } & \multicolumn{6}{|c|}{ Pontuação individual } & \multirow[b]{2}{*}{ 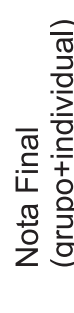 } \\
\hline & 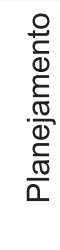 & 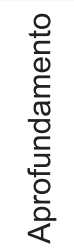 & 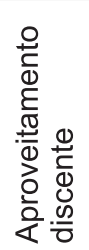 & 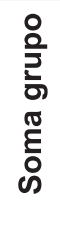 & 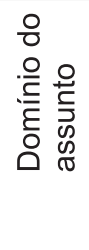 & 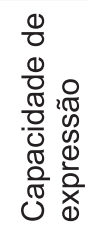 & 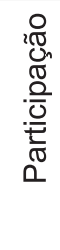 & 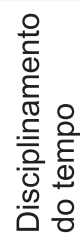 & 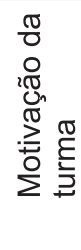 & 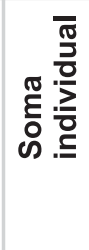 & \\
\hline Aluno 6 & 1,0 & 1,0 & 1,0 & 3,0 & 2,0 & 0,5 & 1,5 & 0,5 & 1,0 & 5,5 & 8,5 \\
\hline Aluno 8 & 1,0 & 1,0 & 1,0 & 3,0 & 1,0 & 1,0 & 1,0 & 0,0 & 1,0 & 4,0 & 7,0 \\
\hline Aluno 15 & 1,0 & 1,0 & 1,0 & 3,0 & 2,5 & 1,0 & 1,0 & 0,5 & 1,5 & 6,5 & 9,5 \\
\hline Aluno 32 & 1,0 & 1,0 & 1,0 & 3,0 & 2,0 & 0,5 & 0,5 & 0,5 & 1,0 & 4,5 & 7,5 \\
\hline
\end{tabular}

\begin{tabular}{|c|c|c|c|c|c|c|c|c|c|c|}
\hline \multicolumn{11}{|c|}{ Pontuação máxima para cada item } \\
\hline \multicolumn{4}{|c|}{ Pontuação do grupo } & \multicolumn{6}{|c|}{ Pontuação individual } & \multirow{2}{*}{ 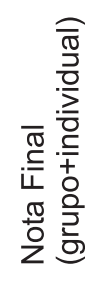 } \\
\hline 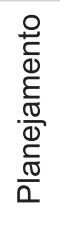 & 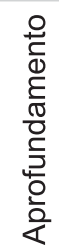 & 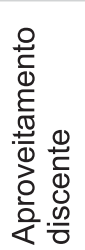 & $\begin{array}{l}\circ \\
\stackrel{\circ}{2} \\
\vdots \\
\tilde{\sigma} \\
\tilde{\sigma} \\
\stackrel{0}{0}\end{array}$ & 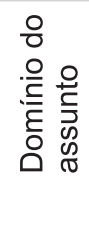 & 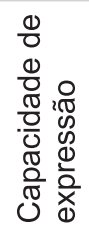 & 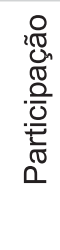 & 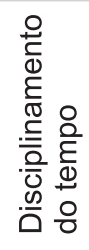 & 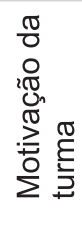 & 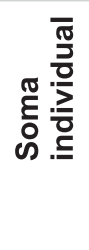 & \\
\hline 1,0 & 1,0 & 1,0 & 3,0 & 2,5 & 1,0 & 1,5 & 0,5 & 1,5 & 7,0 & 10,0 \\
\hline
\end{tabular}




\section{Anexo 3}

\section{Exemplo do mapa de apuração das notas do Ciclo de Aulas em Equipe}

UNIVERSIDADE.

Curso:

Disciplina:

TURMA:

Prof.:

ÉPOCA:

\begin{tabular}{|c|c|c|c|c|c|c|c|c|c|c|}
\hline \multicolumn{11}{|c|}{ Mapa de Apuração das Notas do Ciclo de Aulas em Equipe } \\
\hline \multirow[t]{2}{*}{ Matrícula } & \multirow[t]{2}{*}{$\mathrm{N}^{\circ}$} & \multirow{2}{*}{$\begin{array}{c}\text { Nome } \\
\text { do aluno }\end{array}$} & \multicolumn{2}{|c|}{ Atuação Docente } & \multicolumn{5}{|c|}{ Aproveitamento Discente } & \multirow{2}{*}{$\begin{array}{l}\text { Média } \\
\text { do } \\
\text { Ciclo } \\
\text { (h) }\end{array}$} \\
\hline & & & $\begin{array}{c}\text { Avaliação } \\
\text { feita pelo } \\
\text { professor } \\
\text { (a) }\end{array}$ & $\begin{array}{l}\text { Auto- } \\
\text { avaliação } \\
\text { (b) }\end{array}$ & $\begin{array}{c}\text { Teste } \\
1 \\
(c)\end{array}$ & $\begin{array}{c}\text { Teste } \\
2 \\
\text { (d) }\end{array}$ & $\begin{array}{c}\text { Teste } \\
3 \\
(e)\end{array}$ & $\begin{array}{c}\text { Teste } \\
4 \\
(\mathrm{f})\end{array}$ & $\begin{array}{l}\text { Média } \\
\text { dos } \\
\text { Testes } \\
\text { (g) }\end{array}$ & \\
\hline 00000234 & 01 & Aluno 1 & 9,3 & 9,1 & 5,5 & 5,8 & 10,0 & apres. & 7,1 & 8,8 \\
\hline 00000912 & 02 & Aluno 2 & 8,6 & 9,0 & 6,5 & apres. & 10,0 & 9,0 & 8,5 & 8,7 \\
\hline 00000415 & 03 & Aluno 3 & 9,8 & 9,5 & 0,0 & 5,8 & 10,0 & apres. & 5,3 & 8,8 \\
\hline 00000350 & 04 & Aluno 4 & 9,8 & 9,5 & 5,5 & 5,8 & 9,5 & apres. & 6,9 & 9,2 \\
\hline 00000054 & 05 & Aluno 5 & 6,6 & 9,5 & 6,5 & apres. & 9,5 & 9,5 & 8,5 & 7,6 \\
\hline 00000678 & 06 & Aluno 6 & 8,5 & 8,5 & 5,0 & 7,5 & apres. & 7,0 & 6,5 & 8,1 \\
\hline 00000227 & 07 & Aluno 7 & 7,1 & 10,0 & 6,5 & apres. & 10,0 & 8,0 & 8,2 & 7,9 \\
\hline 00000412 & 08 & Aluno 8 & 7,0 & 8,0 & 5,0 & 7,5 & apres. & 6,0 & 6,2 & 7,0 \\
\hline 00000789 & 09 & Aluno 9 & 0,0 & 0,0 & 0,0 & 0,0 & 0,0 & 0,0 & 0,0 & 0,0 \\
\hline 00000122 & 10 & Aluno 10 & 7,5 & 8,5 & apres. & 6,5 & 10,0 & 7,0 & 7,8 & 7,8 \\
\hline
\end{tabular}

(1) Coluna g: média aritmética simples dos testes (coluna c, d, e e f).

(2) Coluna $\mathbf{h}$ : média ponderada das notas das seguintes colunas e respectivos pesos:

Coluna $\mathbf{a}=$ peso 6 ; coluna $\mathbf{b}=$ peso 2 e coluna $\mathbf{g}=$ peso 2 